\title{
"MEDICATE": TREATING DEPRESSION VIA GAME THERAPY
}

\author{
Devansh Mishra, Ajay Singh, Akash Halder, Anusha Sharma A, Rishika Varshiini Rao \\ Presidency University, \\ Bangalore, India
}

\begin{abstract}
Depression is a common but serious mood disorder. It involves several symptoms which affect the thinking and the day to day activities such as working, eating, or sleeping. Video games have been a very big success in treating and rehabilitating such mental health disorders. We created "Medicate" a video game, to help depressed people recover. It enables the player to experience and overcome those feelings of depression. Through this game, the player might gain a better perspective about the disorder, as it acts as a game therapy.
\end{abstract}

Keywords-depression, game therapy, serious game, mental health

\section{INTRODUCTION}

The misinterpretation of depression, like "it's not a real medical illness" is still believed in many developed countries (Griffiths KM et al. 2016), which leads to stigmatization of depression. This stigmatization makes patients shameful and secretive regarding this mental illness (Wolpert Lewis et al. 2001), and it is found out that during high levels of stress and depression there is a loss of volume in the hippocampus, of about $20 \%$ of its size in a depressed person, the damage caused affects the person's recollection memory (Campbell S et al. 2004; Baune B. T. et al. 2010). Where most of the depression patients who receive antidepressants, terminate their dosage due to the fear of side effects and addiction, this early termination has adverse effects (Melartin TK et al. 2005) due to which these patients must be looked after by physicians and it has been predicted by (Cooper R.A et al. 2002) the experts that in the coming decade there will be a shortage of nurses and physicians, a way to tackle this is by developing applications that can be used by both patients and physicians in which the hidden results can be accessed by the physicians to monitor the changes in a patient's mental state. Advanced computerized technologies can be a solution to expand cognitive-behavioral therapy (CBT), as the use of applications for mental health has increased significantly (Bakker D et al. 2016). Therefore, video games as an interactive medium can provide a cost-effective approach to treat or even prevent depression (Fleming T et al. 2014). Based on this rationale, we have designed Medicate, a game with an emotional atmosphere, where key emotions of depressed people are addressed, and this game is focused on challenging the users in such a way that it activates their brain's reward pathway and hippocampus (Boot WR et al. 2008). It can improve the user's confidence and problem solving skills, making them more prepared to deal with real life instead of feeling the need to escape it.

\section{RELATED WORK}

Many games in the past have targeted the topic of depression, but only a few games have captured the essence of it, such as SPARX (Merry et al. 2012), Sea of Solitude, and Depression Quest. In "Sea of Solitude" Kay, who is a young woman in the game world, suffers from serious mental problems like anger, loneliness, and worthlessness which turns her into a monster. This monster who is a very scary red-eyed creature tries to destroy her. Her emotions also turn out to be a monster where she has to battle between the two to understand how her negative emotions are affecting her. While "SPARX" is a free online e-therapy game which aims in helping young people suffering from mild depression, stress, and anxiety. They use a personality analysis test to understand if SPARX will be helpful to the player in the future. SPARX helps people to resolve their issues and problems in life using CBT. Games like these can be used to treat depression, as it has been proven that games can reduce depressive symptoms (Fleming T et al. 2014).

\section{GAME DESIGN}

\section{A. The Choice}

In the beginning the player has to make a choice about being honest while answering the questionnaire, which is used to evaluate the player's state of mind, based on the player's answer to these questions a hidden score is calculated and it is used to load a particular scene.

The questionnaire is made interactive by associating each question with an object, whenever the player interacts with that particular object, a related question is asked.

\section{B. Dreamscapes}

Every scene in the game except the initial home scene is actually a dream that the player is experiencing as per the storyline, following are the different dreamscapes the player experiences:

1) Beginning: Initially, the player is isolated from the world which resembles the loneliness a person experiences 
during the depression, as soon as the player walks out of the house he is mesmerized by the beauty of a flower and when the player tries to pluck it, a light source in the form of hope is seen.

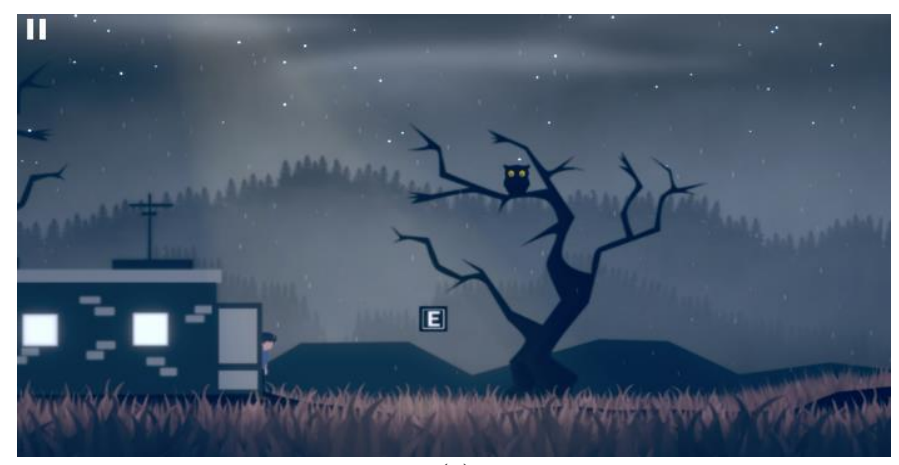

(a)

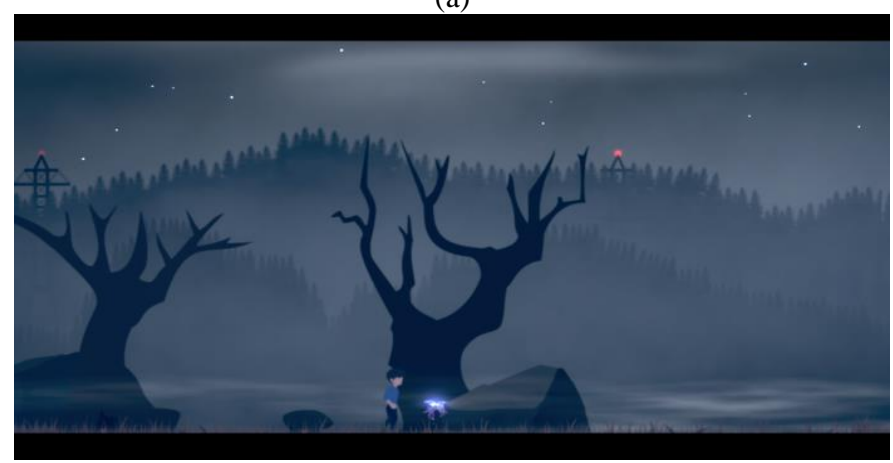

(b)

Fig. 1: Initial transition out of the comfort zone and isolation.

Here leaving the house resembles moving out of comfort zone, which is important to change a person's mindset.

2) Unseen: Once the player is out of his comfort zone, he goes on a journey to understand life, where the light source teaches the player about belief. When the player starts to believe in the beauty of nature, he is able to discover the beauty which was unseen.

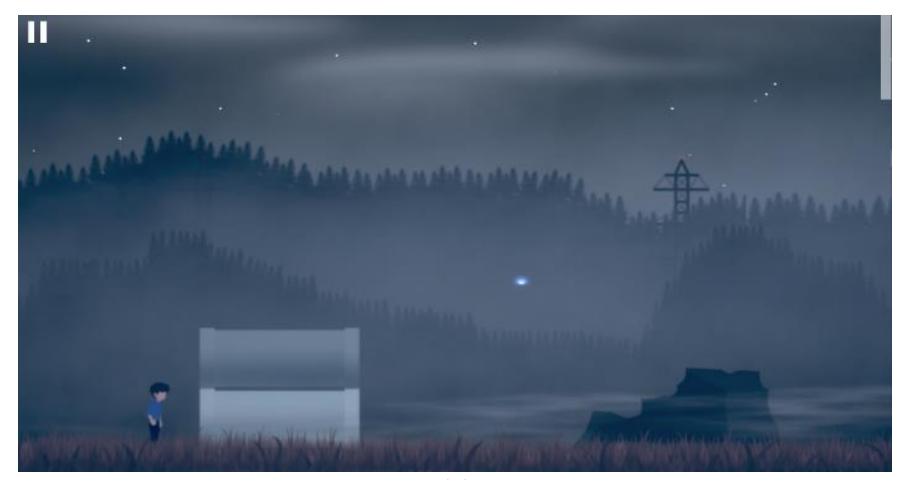

(a)

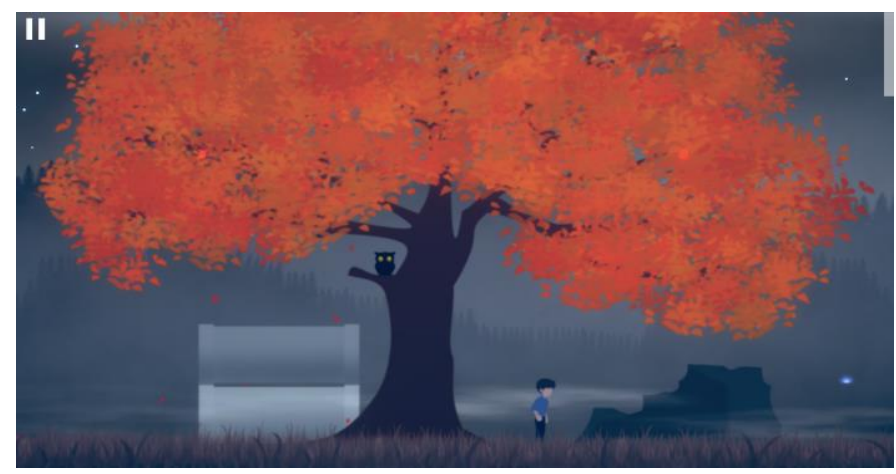

(b)

Fig. 2: Beauty is seen as the blindfold is removed.

Here belief is at the core of recovery, as the person should have faith in order to recover (Green CS et al. 2010).

3) Land of Uncertianty: On this journey through the land of uncertainty the player faces a lot of challenges, one such challenge is the unstable bridge. As the player starts to cross it, it starts to fall down. The bridge represents a problem that isn't permanent but looks so at first, like problems in reality.

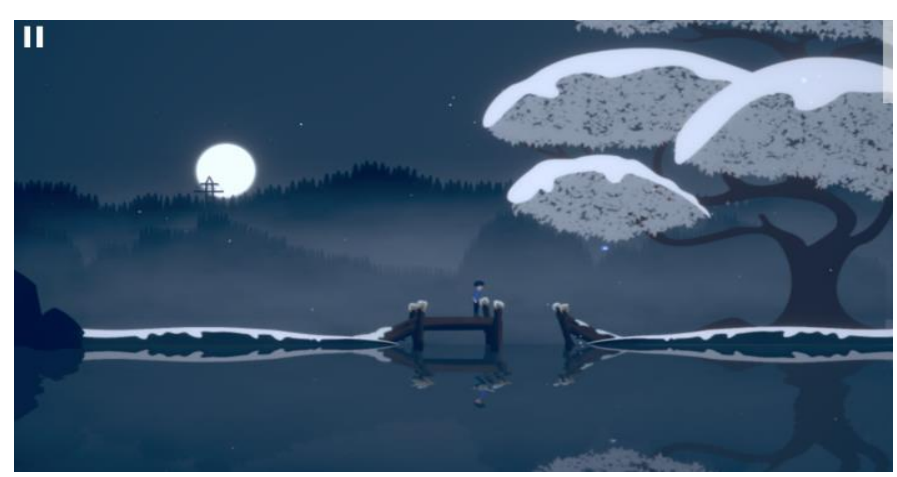

(a)

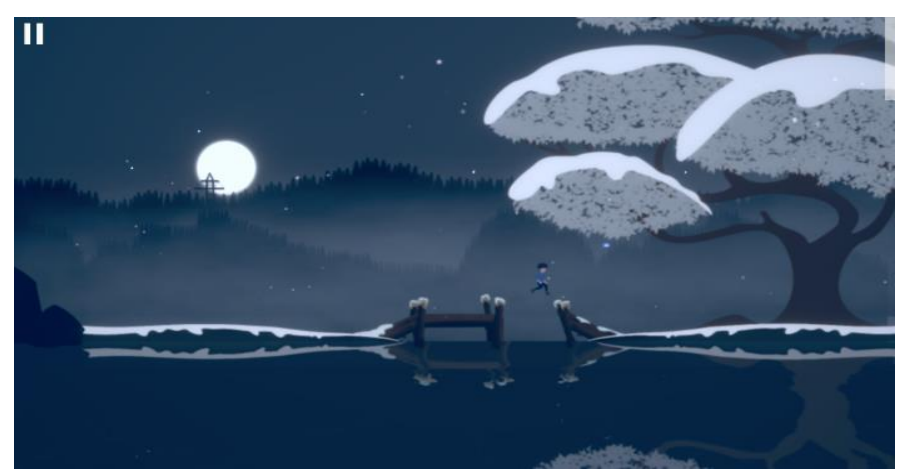

(b)

Fig. 3: Memento Mori - Death is Inevitable.

Once the player learns to face challenges, they move on to the last step of recovery. 
4) Giving Back: Throughout the journey the light source helped the player overcome various obstacles, in the end the player gets a chance to help the light source which is a way of giving back.
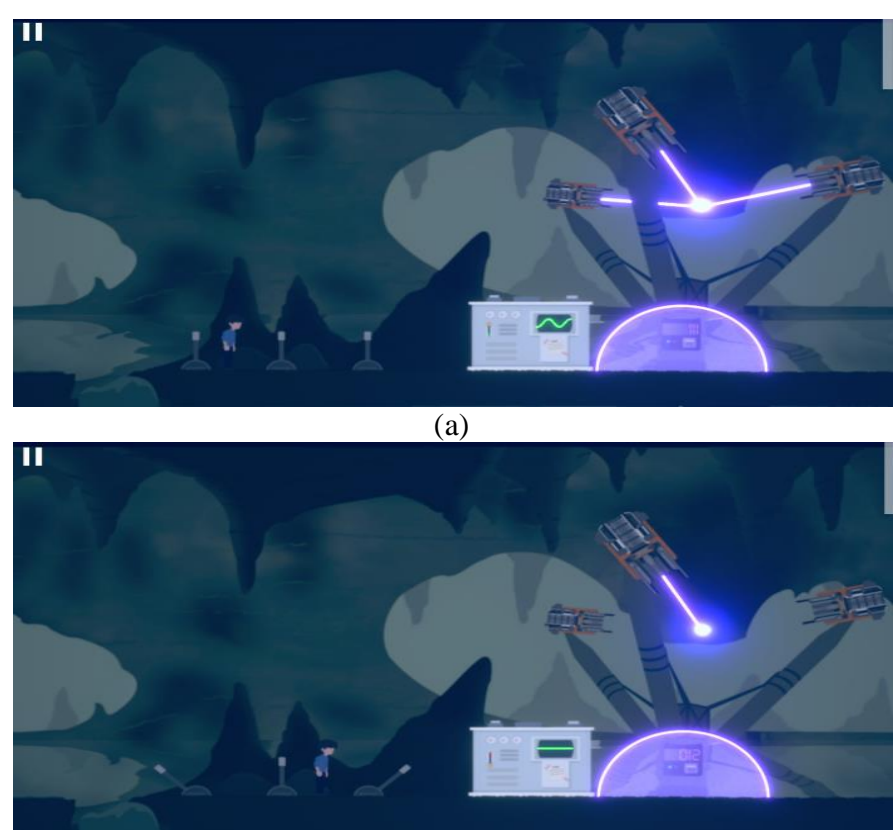

(b)

Fig. 4: Problem solving using the previously learnt game concepts.

Giving back is at the core of gratitude, which is the key to happiness and contentment.

\section{Artwork}

We worked on the game concepts based on the emotions experienced during the depression, the storyboard followed the conceptual art. Classic art techniques such as shading and color grading were used along with post-processing effects to make the environment of the game represent each emotion more vividly. Similar work was done with the main character of the game, where the player is wearing blue clothes representing the constant low mood experienced during depression.

\section{METHODOLOGY}

Medicate, is an exploration game where the player learns to face the emotions experienced in depression. One of the important factors in providing a customized experience for every user is evaluating the mind-set of the player. We accomplish this by asking the player to answer a questionnaire, this questionnaire was modified according to our game requirements which were initially derived from the PRIME-MD diagnostic instrument for basic mental issues (Kroenke K et al. 2001). It is not a testing kit for depression but it can help in determining the level of depression and response to treatment.

TABLE I. PHQ -9 QUESTIONNAIRE

\begin{tabular}{|c|c|c|c|}
\hline \multicolumn{4}{|c|}{ Scoring System } \\
\hline SL No & Question & Option & Score \\
\hline \multirow[t]{3}{*}{1} & \multirow{3}{*}{$\begin{array}{l}\text { Do you think your } \\
\text { future is hopeless? }\end{array}$} & Yes & 1 \\
\hline & & May be & 0.5 \\
\hline & & No & 0 \\
\hline \multirow[t]{3}{*}{2} & \multirow{3}{*}{$\begin{array}{l}\text { Did pleasure and joy } \\
\text { go out of your life? }\end{array}$} & Yes & 1 \\
\hline & & May be & 0.5 \\
\hline & & No & 0 \\
\hline \multirow[t]{3}{*}{3} & \multirow{3}{*}{$\begin{array}{l}\text { Are you facing } \\
\text { difficulty in making } \\
\text { decisions? }\end{array}$} & Yes & 1 \\
\hline & & May be & 0.5 \\
\hline & & No & 0 \\
\hline \multirow[t]{3}{*}{4} & \multirow{3}{*}{$\begin{array}{l}\text { Do you think your } \\
\text { sleep has been } \\
\text { disturbed? }\end{array}$} & Yes & 1 \\
\hline & & May be & 0.5 \\
\hline & & No & 0 \\
\hline \multirow[t]{3}{*}{5} & \multirow{3}{*}{$\begin{array}{l}\text { Did you lose or gain } \\
\text { weight recently? }\end{array}$} & Yes & 1 \\
\hline & & May be & 0.5 \\
\hline & & No & 0 \\
\hline \multirow[t]{3}{*}{6} & \multirow{3}{*}{$\begin{array}{l}\text { Do you require more } \\
\text { effort for small } \\
\text { tasks? }\end{array}$} & Yes & 1 \\
\hline & & May be & 0.5 \\
\hline & & No & 0 \\
\hline \multirow[t]{3}{*}{7} & \multirow{3}{*}{$\begin{array}{l}\text { Have you had any } \\
\text { concentration } \\
\text { trouble? }\end{array}$} & Yes & 1 \\
\hline & & May be & 0.5 \\
\hline & & No & 0 \\
\hline \multirow[t]{3}{*}{8} & \multirow{3}{*}{$\begin{array}{l}\text { Have you had any } \\
\text { suicidal thoughts? }\end{array}$} & Yes & 1 \\
\hline & & May be & 0.5 \\
\hline & & No & 0 \\
\hline
\end{tabular}

Once the player is evaluated, the game loads a certain set of levels based on the severity of depression. Each set has a unique story and gameplay this provides a custom experience for every user. After completing the set of levels, the player again attempts the questionnaire and this is done to measure the patient's response to treatment. If the game isn't effective, the end game message is shown in red, but if it was effective then the end game message is shown in blue.

\section{IMPLEMENTATION}

The game consist of various interrelated key concepts, few of the major development concepts of the game are explained below:

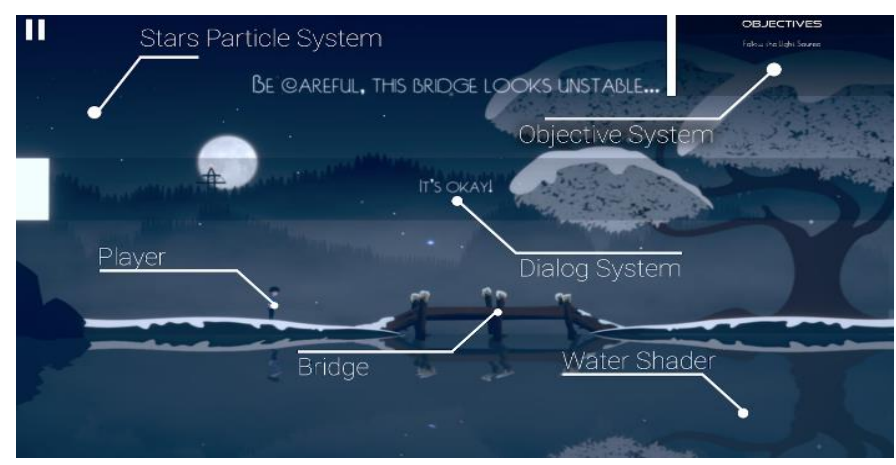

Fig. 5: Various key concepts of the game. 


\section{A. Controllable Character}

The user can control the protagonist of the game i.e. the player. Player's sprite is first created in Photoshop using multiple layers for each body part, then this sprite is used to create a "Sprite Mesh". We paint the bone weights on the sprite mesh using the sprite editor inside unity, and after tweaking the bone depth as per our needs, the overall sprite is rigged. This Rigged Sprite is then used to create animation clips which are linked together inside the animation state machine. A custom character controller script was then created, which enables the character movement based on user interaction.

\section{B. Dialog System}

Dialog system is built from ground up as per our game needs, the dialog system plays a set of dialogs on trigger events. Each dialog set is defined by a set of dialogs which are interlinked together via dialog options. These dialogs help the player to communicate during the gameplay.

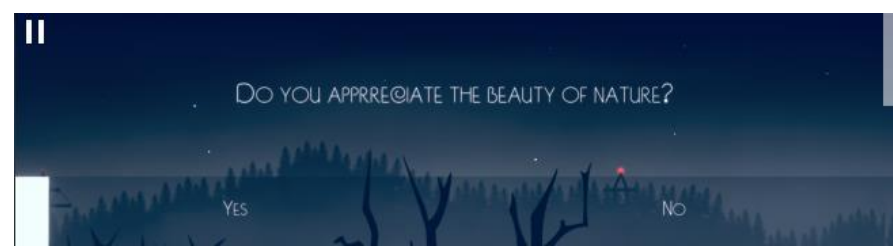

Fig. 6: Dialog System prompting a response from the player.

\section{Objective System}

The objective system assigns the player new tasks to be performed in order to progress in the game. It provides hints to the player, therefore providing them with direction on what to do next.

\section{Asset}

Usually assets are files created outside of unity and are imported into unity. It could be a file that could contain a 3D model, an audio, an image, or any other file that Unity supports. The contents of these files can be used inside a game scene in unity.

\section{E. Audio}

Every audio in the game was first created in "FL Studios" then it was imported into Unity. Inside Unity these audio clips were played with different audio mixers to provide better fidelity. These audio clips were timed using timeline and custom scripts.

\section{F. Sprites}

Sprites are 2D graphics with alpha channels used for characters, props and other elements of gameplay. Photoshop was used to create sprites in our game, vector tracing techniques were used to create many of these sprites from scratch using real life references.

\section{G. Game Object}

A game scene is populated with various game objects, some of which are intractable and dynamic. These game objects often react to the player, providing immersive experience by simulating their presence in the game world. Game object interactions often decide the outcome of the game, these interactions are triggered by the player's actions most of the time.

\section{H. Physics Engine}

To make sure that the laws of physics act upon various game objects we have used the Physics Engine so that they are affected by collisions, gravity, and other factors. We achieved this by using Unity's built-in physics engine.

\section{Scenes}

We have set up the game with a screen box technique that divides the levels into a number of scenes, where the screen box changes when the player switches between the scenes. It is a better technique to avoid unnecessary usage of memory when the required amount of memory is not available, the game may result in unexpected behaviour or even a crash.

\section{J. Shaders}

Shaders define the color of each pixel rendered, based on the lighting input, in order to create these shaders with simplicity we used Unity's in-built tool "Shader Graph". Shader Graphs help in creating shaders for various effects like, distortion, fire, snow, etc. Shader Graph reduces the scripting work required for creating shaders with the help of graphs.

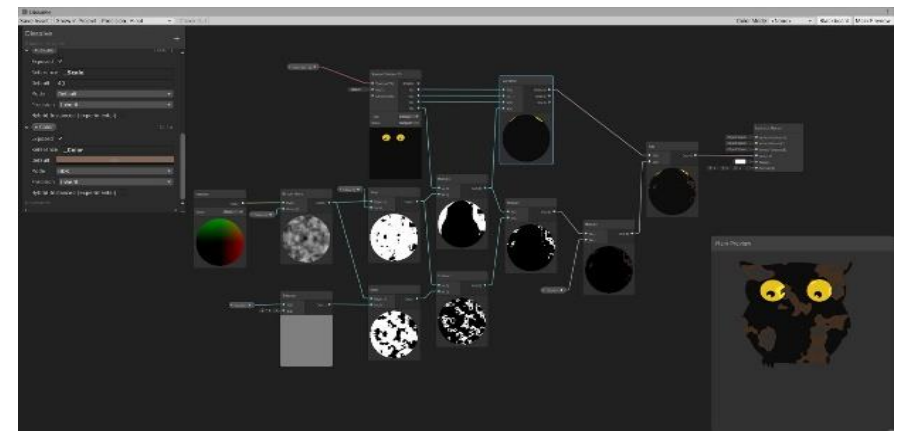

Fig. 7: Shader Graph of Dissolve Effect.

\section{K. 2D Lights}

Unity's experimental feature "2D Lights" were used to light the sprites. Each Sprite's renderer was assigned a material which would react to 2D Lights. Multiple types of 2D Lights are available in Unity, such as freeform, sprite, parametric, point, and global light. We used a combination of these lights in different scenes, to simulate light effects.

\section{Post Processing Effect}

Post-processing is used to enhance the image in the camera viewport, thus improving the game visuals. A global volume 


\section{International Journal of Engineering Applied Sciences and Technology, 2020 \\ Vol. 5, Issue 1, ISSN No. 2455-2143, Pages 274-280 \\ Published Online May 2020 in IJEAST (http://www.ijeast.com)}

profile was used to apply these effects throughout the game, some of the effects were:

1) Bloom: Bloom is used to give an illusion of bright light and it enhances the background ambiance in the scene.

2) Motion Blur: It's an effect that is used to show the apparent movement of an object, it was used during game scene transitions.

3) Lift Gamma Gain: It is a combination of three different ways for color grading in post-processing. Each of which allows to change the dark tones, the mid- range tone and the highlight look brighter respectively.

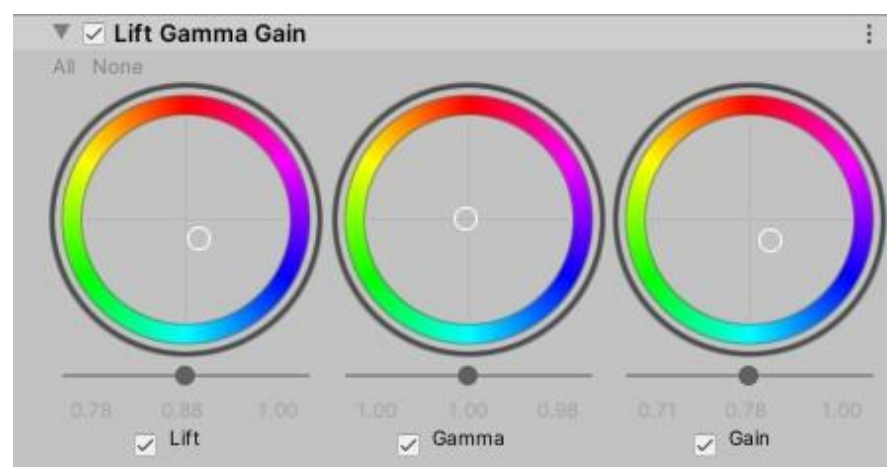

Fig. 8: Lift Gamma Gain Values.

4) Depth of field: It is used to focus the camera on a particular part of the image by blurring the unnecessary background.

5) Vignette: It is used to darken the edges of an image, thus increasing the focus at the center.
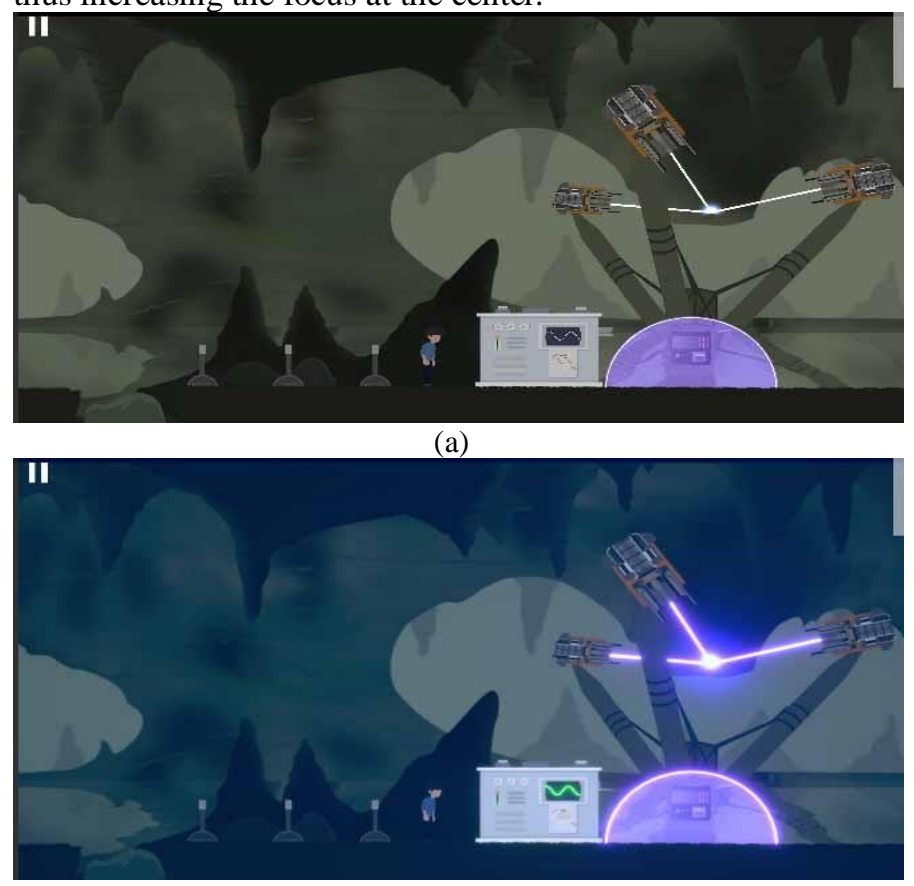

(b)

Fig. 9: Visual Enhancement with Post Processing.

\section{Particle System}

A particle system is used to simulate and render particles in order to produce a visual effect. The system stimulates these particles collectively to create the illusion of a whole effect.

Particle systems are used when we have to give real feel to the players walk, running etc. They are used to give particle effects for various particles like dust, smoke, fire, stars, etc. We used a particle system for creating stars in the sky, fog, aurora, and snow.

\section{N. Timeline}

Timeline was used in the creation of various game cinematics, it was used to create game-play sequences and audio sequences. It contains signals which are received by game objects during cinematic resulting in invocation of custom events.

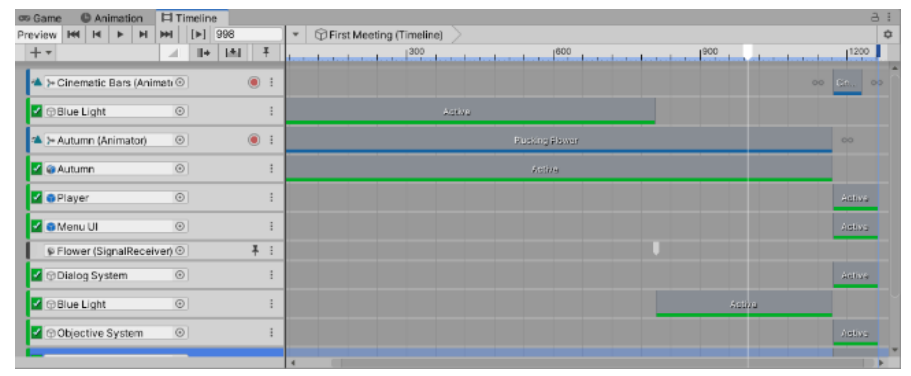

Fig. 10: Timeline which is used for sequencing a cinematic.

These cinematics are used for connecting various parts of the story, this improvises the storytelling

\section{RESULT AND DISCUSSION}

Our main objective was to design a game in such a way that it acts as a tool to reduce depression and anxiety which can be beneficial for people with mild or moderate depression. People may prefer a more viable solution such as gaming rather than consulting a physician due to stigmatization. To evaluate the player's level of depression we used a questionnaire based on PHQ 9 self-administered version to monitor the severity of depression (Kroenke K et al. 2001).

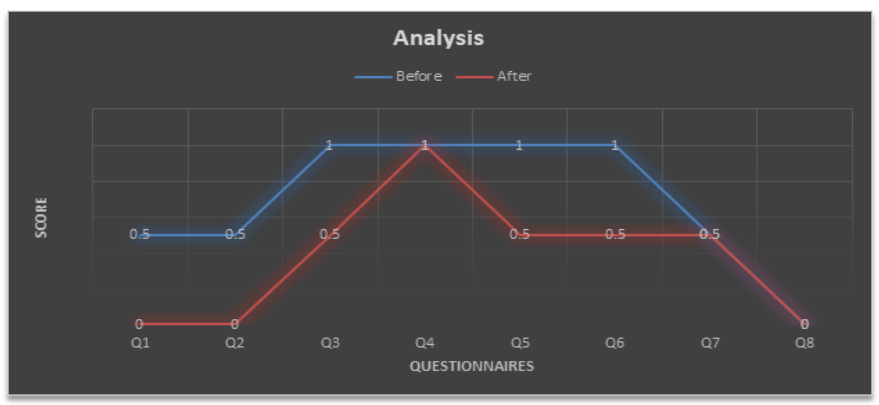

Fig. 11: Analysis of the initial and final scores. 
The following table shows a sample data set of a player:

TABLE II. SAMPLE DATA SET

\begin{tabular}{|l|l|l|l|}
\hline \multirow{2}{*}{ SL No } & \multirow{2}{*}{ Question } & \multicolumn{2}{|l|}{ Score } \\
\cline { 3 - 4 } & & Initial & Final \\
\hline 1 & About hopeless Future & 0.5 & 0 \\
\hline 2 & No pleasure and joy & 0.5 & 0 \\
\hline 3 & Decision making & 1 & 0.5 \\
\hline 4 & Disturbed Sleep & 1 & 1 \\
\hline 5 & Appetite & 1 & 0.5 \\
\hline 6 & Effort & 1 & 0.5 \\
\hline 7 & Concentration problem & 0.5 & 0.5 \\
\hline 8 & Suicidal thoughts & 0 & 0 \\
\hline TOTAL SCORE & 5.5 & 3 \\
\hline
\end{tabular}

The above analysis shows the difference in the player's state of mind before and after playing the game. From the analysis, we can say that we obtained a positive result as the end score is lower than the initial score, which states that the player has improved. The result may differ according to the player's mindset.

The work of a therapist not only involves providing the right kind of exercises but also provides emotional and physical support to the people and tracks their performance. As there is a time constraint, a therapy session can't be cut short.

Video games should be easy to use and should monitor the status by using an automated system, it shouldn't be more time consuming. Gaming therapy isn't a replacement of traditional therapy, it's there to help increase the effectiveness of treatment (Anguera J.A. et al. 2016).

When gaming therapy is used, it should be flexible and it should help them track the performance of the players. Moreover gaming therapy can be used on multiple test subjects at once, which can help save time and increase productivity.

Therapists will always be needed to provide the mental support and act as a coach to guide the players while examining them during the training period. Presence of a physician is also necessary if there are senior participants as they may need assistance for using games which involve physical training and play in the appropriate seating position to avoid any further injuries or sprains.

\section{FUTURE WORK}

In the future we are planning to conduct beta testing for the game, in order to improvise its overall gameplay by making it immersive. In order to evaluate the effectiveness of the game, we will be conducting user testing on depressed and healthy users. It is planned to be published on the web and mobile platforms. This will be the future development approach.

\section{VIII.CONCLUSION}

Through this paper, we have presented a framework to monitor people's severity of depression with the use of a selfadministered version of the PHQ 9 questionnaire module which was implemented in our game "Medicate". It is a cognitive behavioral therapy based game that consists of several in-game challenges that are solved with the help of various interactive modules. Which in turn improves the condition of the hippocampus and the reward pathways in the patient.

\section{ACKNOWLEDGMENT}

We wish to acknowledge Dr. T.K. Thivakaran, and Professor Sanjeev P. Kaulgud of the Computer Science Department for their thorough supervision, suggestions, and inputs made during the course of game development.

\section{REFERENCES}

[1] Griffiths, K. M., Nakane, Y., Christensen, H., Yoshioka, K., Jorm, A. F., \& Nakane, H. (2006). Stigma in response to mental disorders: a comparison of Australia and Japan. BMC psychiatry, 6, 21. https://doi.org/10.1186/1471-244X-6-21

[2] Wolpert, L. (2001). Stigma of depression - a personal view. British Medical Bulletin, 57(1), 221-224. https://doi.org/10.1093/bmb/57.1.221

[3] Campbell, S., \& Macqueen, G. (2004). The role of the hippocampus in the pathophysiology of major depression. Journal of psychiatry \& neuroscience : $J P N, 29(6), 417-426$.

[4] Baune B. T., Miller R., McAfoose J., Johnson M., Quirk F., Mitchell D. (2010). The role of cognitive impairment in general functioning in major depression. Psychiatry Res. 176, 183-189. 10.1016/j.psychres.2008.12.001

[5] Melartin, T. K., Rytsälä, H. J., Leskelä, U. S., Lestelä-Mielonen, P. S., Sokero, T. P., \& Isometsä, E. T. (2005). Continuity is the main challenge in treating major depressive disorder in psychiatric care. The Journal of clinical psychiatry, 66(2), 220227. https://doi.org/10.4088/jcp.v66n0210

[6] Cooper, R. A., Getzen, T. E., McKee, H. J., \& Laud, P. (2002). Economic and demographic trends signal an impending physician shortage. Health affairs (Project Hope), 21(1), 140-154. https://doi.org/10.1377/hlthaff.21.1.140 
[7] Bakker, D., Kazantzis, N., Rickwood, D., \& Rickard, N. (2016). Mental Health Smartphone Apps: Review and Evidence-Based Recommendations for Future Developments. JMIR mental health,3(1), e7. https://doi.org/10.2196/mental.4984

[8] Fleming, T. M., Cheek, C., Merry, S. N., Thabrew, H., Bridgman, H., Stasiak, K., ... Hetrick, S. (2015). Juegos serios para el tratamiento o la prevención de la depresión: una revisión sistemática. Revista De Psicopatología y Psicología Clínica, 19(3), 227. doi: 10.5944/rppc.vol.19.num.3.2014.13904

[9] Green CS, Li R, Bavelier D (2010) Perceptual learning during action video game playing. Topics in Cognitive Science 2: 202-216.

[10] Boot WR, Kramer AF, Simons DJ, Fabiani M, Gratton G (2008) The effects of video game playing on attention, memory, and executive control. Acta Psychologica 129: 387-398.

[11] Merry, S. N., Stasiak, K., Shepherd, M., Frampton, C., Fleming, T., \& Lucassen, M. F. (2012). The effectiveness of SPARX, a computerised self help intervention for adolescents seeking help for depression: randomised controlled non-inferiority trial. BMJ (Clinical research ed.), 344, e2598. https://doi.org/10.1136/bmj.e2598.

[12] Kroenke, K., Spitzer, R. L., \& Williams, J. B. W. (2001). The PHQ-9. Journal of General Internal Medicine, 16(9), 606-613. https://doi.org/10.1046/j.15251497.2001.016009606.x

[13] Anguera J. A., Gunning F. M., Arean P. A. (2016). Improving late life depression and cognitive control through the use of therapeutic video game technology: A proof-of-concept randomized trial. Depression and Anxiety. doi:10.1002/da.22588. 